\title{
Estratégias de leitura utilizadas por licenciandos de áreas distintas para lerem textos de estudo
}

\section{Reading strategies used by undergraduates from different areas to read study texts}

\author{
Diesse Garcia Gimenes ${ }^{1}$; Elsa Maria Mendes Pessoa Pullin²
}

Resumo

O presente trabalho, de natureza exploratória, objetivou investigar as estratégias de leitura utilizadas por alunos matriculados em distintos cursos de licenciatura de uma IES pública. A opção para a seleção de alunos de licenciatura deve-se a que eles, como futuros professores, independente da disciplina que venham a ministrar, serão responsáveis pela formação de seus alunos como leitores. Os alunos participantes $(\mathrm{N}=366)$ encontravam-se matriculados no primeiro e quarto ano dos cursos de Biologia $(\mathrm{n}=59)$, Filosofia $(\mathrm{n}=32)$, Geografia $(\mathrm{n}=124)$, Letras Clássicas e Vernáculas $(\mathrm{n}=106)$ e Matemática $(\mathrm{n}=45)$. Para a coleta de dados, foi utilizada a Escala de Estratégias de Leitura, traduzida e adaptada por Kopke Filho, e informado que, ao responderem, deveriam ter por foco a leitura dos textos prescritos em seu curso. Comparações entre as séries e áreas dos cursos foram realizadas. De modo geral, os resultados assinalam que alunos do último ano do curso informam utilizar com mais frequência estratégias de leitura que favorecem uma leitura mais apropriada dos textos acadêmicos ${ }^{3}$ prescritos. A necessidade de os professores do Ensino Superior se preocuparem ensinar os alunos a lerem os textos que prescrevem é ressaltada.

Palavras-chave: Leitura. Estratégias de leitura. Ensino superior.

\begin{abstract}
This work was exploratory in nature, aimed at investigating the reading strategies used by students enrolled in different degree courses of a public University. The option of selecting undergraduate students was due to the fact that they, as future teachers, will be responsible for training their students as readers, regardless the subject they teach. The participating students $(\mathrm{N}=366)$ were enrolled in the freshman and senior year in the courses of Biology $(n=59)$, Geography $(n=124)$, Languages $(n=106)$, Mathematics $(n=45)$ and Philosophy $(n=32)$. In order to collect data it was used the Scale of Reading Strategies, translated and adapted by Kopke Son. The participants were informed that the answers should focus the reading of the texts assign in their courses. Comparisons focusing different series and areas of knowledge were made. In general, the results indicate that senior students report regularly using reading strategies that promote a more appropriate reading of the academic texts assigned. The need for teachers of higher education to focus on teaching students how to read the texts that are assigned is stressed.
\end{abstract}

Keywords: Reading. Reading strategies. Higher education.

1 Aluna do Curso de Pedagogia da Universidade Estadual de Londrina. Email: diesse_gimenes@hotmail.com

2 Docente do Departamento de Educação da Universidade Estadual de Londrina(UEL)._Londrina. Paraná. Brasil.elsapessoapullin@ gmail.com

3 Toma-se, no presente trabalho, a terminologia "textos acadêmicos" para se referir aos textos prescritos por professores do Ensino Superior para seus alunos estudarem. 


\section{Introdução}

O modelo cultural e educativo que prevalece nas sociedades ocidentais atuais, segundo GimenoSacristán (2008), é orientado para a busca da formação humana. Decorre dessa meta a importância de as diferentes agências sociais, especialmente as escolares, prepararem adequadamente os indivíduos para ler e escrever o que está armazenado na escrita, além de os capacitarem para que possam ter acesso aos diferentes suportes nos quais os conhecimentos anteriores e os contemporâneos estejam veiculados. Esses são alguns dos aspectos culturais positivamente valorizados, porque esse modelo "[...] concede importância à ação e à atitude de se informar, à leitura como meio de se inserir no mundo enquanto seres reflexivos, continuando a aprender de forma autodidacta a partir do texto escrito [...]" (GIMENO-SACRISTÁN, 2008, p. 89).

Concordamos com o autor quanto à relevância e ao "[...] valor instrumental que a leitura tem na vida das pessoas para participarem na sociedade do conhecimento [... condição da cidadania e da inclusão social" (GIMENO-SACRISTÁN, 2008, p. 89), bem como com Tedesco (2011, p. 31), quando pondera acerca da importância dos dois pilares em que se deve assentar a educação escolar básica para responder aos desafios do século XXI: "aprender a aprender e aprender a viver juntos" caso a escola e os que nela trabalham objetivem a construção de uma sociedade mais justa. Não só são desafios distintos daqueles do passado, como revelam as mudanças do papel e do lugar da educação nos dias de hoje, pelo fato de a "globalização crescente em todas as dimensões da sociedade" (TEDESCO, 2011, p. 35) ter gerado, como efeito principal, o aumento significativo da desigualdade social.

Entretanto não estamos, com isso, defendendo que a escola deva assumir papéis de natureza assistencialista. Pelo contrário, em um sentido amplo, o currículo escolar deve priorizar o conhecimento e a cultura em relação a quaisquer outras ações. Interessa-nos, aqui, a posição de Nóvoa (2010), quando retoma Olivier Reboul, para enfatizar que a escola deve ensinar tudo o que une e tudo o que liberta. Na opinião desse educador e sociólogo, compete à escola ensinar as ferramentas básicas do conhecimento e da cultura, porque só assim as desigualdades sociais e de oportunidades podem ser menos agudas em uma determinada sociedade. Esse autor assinala, ainda:

[...] em vários países, embora a política educacional seja única, verifica-se um dualismo cada vez mais acentuado: as elites investem na Educação privada, cuja base estrutural é a aprendizagem, enquanto as escolas públicas estão cada vez mais centradas em dimensões sociais e assistenciais. Essa Educação feita em duas velocidades é o pior dos cenários para o nosso futuro, pois só aumenta a desigualdade de oportunidades (NÓVOA, 2010, grifo nosso).

Em sendo assim, hão de serem lembradas, de um lado, as palavras de Paulo Freire quando afirma: "Nas culturas letradas, sem ler e sem escrever, não se pode estudar, buscar conhecer, apreender a substantividade do objeto, reconhecer criticamente a razão de ser do objeto" (FREIRE, 2001, p. 87) e, por outro, as ponderações de Gimeno Sacristán, quando afirma:

O inimigo da leitura não reside, como actualmente alguns temem, na cultura audiovisual que domina os meios de comunicação e na extensão das novas tecnologias, mas nas desafortunadas práticas de leitura dominantes a que submetemos os nossos alunos durante a escolaridade (GIMENO-SACRISTAN, 2008, p. 87 , grifo nosso).

Apesar de a imprensa e os discursos de algumas editoras de livros didáticos, de modo geral, “[...] denunciarem o baixo grau de letramento de docentes" (BATISTA, 1998, p. 24), resultados de pesquisa não autorizam a que simplesmente aceitemos essa representação social acerca da leitura de docentes. Isso porque eles vivem em comunidades letradas. Eles devem, ao contrário, ser compreendidos "[...] como leitores que, submetidos 
a condições bem determinadas de formação de leitura, tendem a desenvolver modos específicos de ler e de se relacionar com o impresso e a cultura que os envolvem" (BATISTA, 1998, p. 27, grifo nosso).

Os professores, como sujeitos socioculturais, ao longo da sua vida pessoal e profissional, foram-se construindo e constituindo como leitores. Em outras palavras, as condições facultadas pela escolarização a que foram submetidos e as propiciadas pelas demais agências de socialização configuram os contornos e o perfil que os revelam como leitores. Como a escola é a principal agência, porque socialmente responsável, para ensinar as novas gerações a ler, inclusive quando recebe alunos no Ensino Superior, consideramos importante o fato de se investigar como futuros professores leem os textos que lhes são indicados em seus cursos, mesmo que isso seja conduzido em pesquisas descritivas de caráter exploratório, como a realizada neste trabalho.

Uma das razões da importância desses estudos relaciona-se àquela que, entre outras aprendizagens, deve promover a formação de novos leitores. Em nossa opinião, é a mais relevante, porém nem sempre compartilhada por professores de outras disciplinas, além dos de Língua Portuguesa, no que concordamos com Guedes e Souza (2003).

No Brasil, as políticas públicas de educação têm como marco legal o disciplinado pela atual Lei de Diretrizes e Bases (LDB 9394/96), a qual estipula em suas Disposições Transitórias que, a partir de 2007, isto é, no final da Década da Educação, "somente serão admitidos professores habilitados em nível superior ou formados por treinamento em serviço" (BRASIL, 1996, p. 30). Por conseguinte, esse marco legal estipula qual o tipo de formação exigida para o exercício profissional do magistério. Além desse marco, a edição dos Parâmetros Curriculares Nacionais (BRASIL, 2004), com o intuito de que estes se constituíssem em um "[...] referencial de qualidade para a educação no Ensino Fundamental em todo o País" (BRASIL, 2004, p. 10), entre os demais discursos oficiais, acaba evidenciando a preocupação, por parte de alguns que colaboraram para a redação dos documentos reguladores que lhe seguiram, quanto a quem estaria apto para lêlos, como atesta o trabalho de Batista (1999), por exemplo.

Essas ponderações justificam a necessidade de os professores, em sua formação inicial, serem preparados para lerem, entre outros, textos daquela natureza. Como, para serem professores, precisam ser certificados no Ensino Superior, preferencialmente em cursos de licenciatura, a seleção dos participantes de cursos que certificam para o ensino na Educação Básica teve essa razão.

No Ensino Superior, os alunos precisam ser autônomos e críticos em suas leituras, de modo que possam, além de identificar as ideias e conceitos propostos pelo autor para a problemática abordada, cotejar criticamente as estratégias usadas na argumentação do autor para defender seus pontos de vista e posições e, assim, poderem realizar uma interpretação pessoal das leituras (OLIVEIRA; SANTOS, 2005). Entretanto, muitos desses alunos apresentam dificuldades para alcançar esse desempenho, visto que adquiriram, ao longo da escolarização anterior, concepções equivocadas quanto ao que seja produzir uma leitura como atividade individual e ao que seja aprendizagem, inclusive a que pode ser obtida pela leitura. Esse fato ocorre porque eles frequentemente, estão acostumados a reproduzir as informações dos textos, ao invés de as construírem (SANTOS et al., 2006). Compreendendo a leitura como instrumento importantíssimo para a vida pessoal e profissional, especialmente ao longo de sua formação e constituição como leitor, concordamos com Kons (2005), quando assinala que "o professor pode fazer a diferença na formação de leitores, sobretud se se despir de seu poderio professoral e vestir-se de uma nova autoridade - a que sabe mediar a construção de conhecimentos pelos aprendizes".

Bamberger (1986) destaca que a leitura, desde o início de seu ensino, deve ser trabalhada com os 
alunos em suas diversas modalidades e suportes, não se restringindo ou limitando-se a um único tipo de escrito. Ao assim proceder, o professor poderá encaminhar seus alunos a conhecerem as modalidades e suporte distintos da escrita, bem como os diferentes modos de produzir sua leitura.

Em cursos de graduação, os alunos são levados a lidar diariamente com textos científicos. Seus professores, ao indicá-los, esperam que os alunos possam não só identificar as ideias neles apresentadas, assim como o modo pelo qual o problema ou questão é abordado por um autor, pelas estratégias que utiliza. Para tanto, uma interpretação e diálogo com o texto são necessários pela interação entre as novas informações e as que o aluno já dispunha, viabilizando uma construção do conhecimento (MARTINS; SANTOS; BARIANI, 2005).

Dentre os diversos tipos de leitura que acontecem ao longo da formação profissional em Ensino Superior, a leitura de estudo a partir de textos científicos é indispensável. Ela auxilia e permite ao aluno aprender desde que dialogue com o texto. Contudo, como explica Carlino (2003, p. 1): “o caráter implícito do conhecimento contido nos textos como as práticas leitoras, que os docentes consideram naturais (e não culturais), colocam obstáculos ao desenvolvimento de muitos estudantes". De fato, à maioria dos alunos universitários, raramente foi ensinada a ler esses tipos de textos, por isso enfrentam dificuldades ao cumprir as leituras prescritas em seus cursos (WITTER, 1996; 1997; CARLINO, 2003).

Para que essa dificuldade não aconteça, o aluno, quando lê, precisa circunscrever, inicialmente, o texto na obra do autor e no corpo de conhecimentos na área e dos que dispõe como leitor. Precisa, ainda, identificar e avaliar as principais informações que o autor do texto está apresentando, o que lhe exige ações comuns a quaisquer diálogos. Isto é, o leitor deve ter adquirido conhecimentos e uma postura crítica que lhe permitam dialogar com a produção do autor, inclusive com os recursos que utiliza para apresentar o texto. Quando desse exercício de interação com o texto, a escuta, um consentimento e uma atitude inquisitiva se fazem necessários para que ele possa aprender à medida que lê o texto. Como indicou Paulo Freire: "Estudar seriamente um texto é estudar o estudo de quem, estudando, o escreveu" (FREIRE, 1982, p. 9).

O estudo que se vale da leitura de textos exige, portanto, implicação por parte do leitor, expressa em atitudes e comportamentos cognitivos, adquiridos pela prática (CASTELLO-PEREIRA, 2003). Para que a leitura de textos propostos para estudo aconteça satisfatoriamente, o uso de algumas estratégias de leitura auxilia o leitor a sistematizar e a compreender o texto.

Em suma, no Ensino Superior, é de suma importância que os alunos realizem leituras de textos científicos com compreensão. Quanto mais conhecimento e familiaridade os alunos tiverem com o mundo da leitura, melhor se sairão no cumprimento de suas tarefas (MARTINS; SANTOS; BARIANI, 2005). Estudos sobre a avaliação da compreensão leitora entre universitários realizados, por exemplo, por Silva e Santos (2004), revelam que ocorre uma correlação alta entre os níveis de compreensão em leitura e o desempenho acadêmico dos alunos.

Neste trabalho, focaliza-se o comportamento de leitura de alunos de cursos de licenciatura, especificamente quanto aos tipos de estratégias mais frequentemente (re)conhecidas como utilizadas. Um projeto mais amplo ${ }^{4}$ inclui a participação de outros alunos e o uso de distintos instrumentos para caracterizar as funções atribuídas à leitura, memória em suas formações como leitores, práticas e fontes de leitura. O presente relato é um recorte das informações colhidas nesse projeto mais amplo.

4 Projeto registrado na PROPPG da UEL, sob no. 04945. Contou com apoio financeiro da Fundação Araucária. 
Pesquisas anteriores, como as de Kopke Filho (2001; 2002), de Pullin (2007) e de Pullin e Pullin (2007), têm demonstrado que a utilização dessas estratégias de leitura auxiliam a compreensão e o exercício da autonomia de quem as usa.

\section{O Contexto e o Processo de Geração dos Dados}

A pesquisa foi realizada em uma IES pública, localizada no interior do Estado do Paraná, que atendia 18.764 alunos em 2010. Destes, 15.363 encontravam-se matriculados em um dos 41 cursos de graduação e 3.401 em cursos de pós-graduação: 2.212 em um dos 111 cursos de especialização e em uma das 48 residências na área da saúde, 1.516 alunos realizavam, na época, um dos 16 programas de Doutorado, ou um dos 37 de Mestrado, ou um dos dois de mestrados profissionais ofertados por essa instituição.

Para a parte empírica deste estudo, foram selecionados alunos matriculados em cursos de licenciatura de áreas distintas. Os cursos selecionados foram: Letras Clássicas e Vernáculas, Filosofia, Biologia, Geografia e Matemática. Os cursos de Matemática e Geografia são ofertados pela IES nos períodos matutino e noturno, o curso de Letras é ofertado nos períodos vespertino e noturno, Filosofia apenas no período noturno e o de Biologia é o único em tempo integral (manhã e tarde). A opção em selecionar alunos com habilitação em Licenciatura deve-se à importância de identificar o uso de estratégias entre futuros professores, já que estes terão como responsabilidade a formação de seus alunos como leitores.

O projeto obteve aprovação (197/09) pelo Comitê de Ética em Pesquisa envolvendo seres humanos UEL/ Hospital Universitário Regional Norte do Paraná em dezembro de 2009.

\section{Participantes}

O critério de seleção dos participantes ocorreu a partir da assinatura do Termo de Consentimento Livre e Esclarecido dos alunos matriculados no $1^{\circ} \mathrm{e}$ no $4^{\circ}$ ano dos cursos de licenciatura já mencionados.

Contribuíram para a coleta de dados, 366 alunos matriculados. Do curso de Letras, participaram alunos do turno vespertino e noturno, de Filosofia e Matemática, os participantes eram do período noturno, de Geografia, houve alunos de ambos os turnos. Entre os participantes, 213 alunos encontravam-se matriculados no $1^{\circ}$ ano e 153 no $4^{\circ}$ ano de graduação.

A Tabela 1 permite uma visualização geral do número de participantes em relação aos matriculados por curso e série a que pertenciam.

Tabela 1. Distribuição dos Participantes por Curso e Série.

\begin{tabular}{lccccc}
\hline \multirow{2}{*}{ Cursos } & \multicolumn{3}{c}{ Série } \\
\cline { 2 - 3 } & \multicolumn{2}{c}{$\mathbf{1}^{\mathbf{a}}$} & & \multicolumn{2}{c}{$\mathbf{4}^{\mathbf{a}}$} \\
\cline { 2 - 3 } \cline { 5 - 6 } & Matriculados & Participantes & & Matriculados & Participantes \\
\hline Letras Clássicas e Vernáculas & 109 & 80 & & 87 & 26 \\
Filosofia & 45 & 21 & & 42 & 11 \\
Biologia & 67 & 18 & & 58 & 41 \\
Geografia & 91 & 67 & & 61 & 57 \\
Matemática & 55 & 27 & & 25 & 18 \\
Totais & 367 & 213 & & 273 & 153 \\
\hline
\end{tabular}

Fonte: Do Autor 
Dos 367 alunos matriculados na $1^{\text {a }}$ série dos cursos de licenciatura selecionados, mais da metade participou (58\%). O mesmo, mas em menor quantidade relativa, aconteceu com os matriculados na última série: dos 273 matriculados, participaram 56\%. Como pode ser observado na Tabela 1, a participação foi distinta por curso. No curso de Letras Clássicas e Vernáculas, participaram 73,4\% dos matriculados na $1^{\text {a }}$ série e $29,9 \%$ da $4^{\text {a }}$ série. No curso de Filosofia, participaram 46,7\% dos matriculados na série inicial e $26,2 \%$ dos formandos. Do curso de Biologia, 26,9\% dos recém-ingressos e $70,7 \%$ dos formandos. Do curso de Geografia, contamos com $73,6 \%$ e $93,4 \%$ dos alunos matriculados, respectivamente, na $1^{\mathrm{a}}$ e $4^{\mathrm{a}}$ série do curso. Finalmente, no curso de Matemática, essa participação foi, respectivamente, de 49,1\% e $72 \%$.

\section{Materiais}

Para a coleta de dados foi utilizada a Escala das Estratégias de Leitura de Goetz e Palmer, de 1991, traduzida e adaptada por Kopke Filho em 2001.

O instrumento é composto por 20 itens, divididos em três momentos. O primeiro momento elenca estratégias que podem ser usadas antes da leitura propriamente dita do texto, e comporta os quatro primeiros itens. $\mathrm{O}$ segundo momento refere estratégias passíveis de serem utilizadas durante a leitura, e é composto por 10 itens. O último momento relaciona estratégias que podem ser utilizadas após a leitura, com seis itens. Cada item apresenta, após seu enunciado, a possibilidade do respondente informar a frequência com que utiliza a estratégia enunciada no item. As opções estão dispostas sob a modalidade Likert e o respondente deve assinalar uma delas: frequentemente, algumas vezes e raramente.

\section{Procedimentos}

Após consulta da coordenadora do Projeto e obtida autorização dos colegiados dos respectivos cursos para a execução da pesquisa junto aos alunos, o dia para a coleta de dados foi agendado pela pesquisadora junto ao coordenador dos respectivos cursos.

A coleta ocorreu em uma única sessão por série e curso, em horário de aula cedido para este fim, com a presença do professor da disciplina daquele horário. Cada sessão de coleta foi iniciada com uma apresentação geral do projeto de pesquisa realizada pela pesquisadora, a qual salientou os objetivos da pesquisa e informou aos alunos presentes a possibilidade de participarem ou não em função do aceite voluntário. Em seguida, entregou o Termo de Consentimento Livre e Esclarecido (TCLE), deixando livre a decisão de este ser preenchido e assinado.

A aplicação propriamente dita dos dados aconteceu após o recolhimento do TCLE assinado e compreendeu os meses de março a abril de 2010.

\section{Resultados e Discussão}

Com vistas à análise quantitativa dos dados relativos às informações recolhidas, isto é, às opções assinaladas pelos participantes quanto à frequência de uso das estratégias, foram utilizados pesos distintos para cada uma dessas frequências: Frequentemente $=3$; Algumas vezes $=2 ;$ Raramente $=1$.

Dessa forma, caso todos os participantes utilizassem frequentemente em todas as estratégias, o total máximo de pontuação dos participantes seria de 639 e, caso usassem raramente em todas as estratégias, o máximo de pontuação prevista pelo instrumento seria de 459 pontos. A Tabela 2 apresenta essas pontuações por curso e série. 
Tabela 2. Pontuações Máxima e Mínima Previstas por Curso e Série.

\begin{tabular}{lccccc}
\hline Cursos & \multicolumn{3}{c}{ Série } \\
\cline { 2 - 4 } & \multicolumn{2}{c}{$\mathbf{1}^{\mathbf{a}}$} & & \multicolumn{2}{c}{$\mathbf{4}^{\mathbf{a}}$} \\
\cline { 2 - 3 } \cline { 5 - 6 } & Frequentemente & Raramente & & Frequentemente & Raramente \\
\hline Letras Clássicas e Vernáculas & 240 & 80 & & 78 & 26 \\
Filosofia & 63 & 21 & & 33 & 11 \\
Biologia & 54 & 18 & & 123 & 41 \\
Geografia & 201 & 67 & & 171 & 57 \\
Matemática & 81 & 27 & & 54 & 18 \\
Totais & 639 & 213 & & 459 & 153 \\
\hline
\end{tabular}

Fonte: Do Autor

Quando analisadas as pontuações obtidas pelos participantes, verificou-se que poucos foram os que deixaram de assinalar uma das opções do instrumento. Entre os participantes da $1^{\mathrm{a}}$ série, constatou-se que, no curso de Geografia, 5,5\% deles não assinalou qualquer das opções das estratégias relacionadas à situação depois da leitura. Dos participantes de Matemática, 4\% deixaram de responder às estratégias que o instrumento prevê para durante a leitura. Para as estratégias antes da leitura, o maior índice de abstenção foi registrado entre os participantes dos cursos de Letras Clássicas e Vernáculas (2,9\%).

A Tabela 3 apresenta a incidência de uso das estratégias propostas pelo instrumento por parte dos participantes da $1^{\mathrm{a}}$ série dos cursos selecionados e o índice de abstenção de respostas.

Tabela 3: Uso das Estratégias de Leitura entre Alunos Recém-Ingressos nas Licenciaturas

Uso das Estratégias de Leitura Geografia Biologia Matemática Letras Clássicas e Vernáculas Filosofia

\begin{tabular}{lllllc} 
& $\mathbf{( n = 6 7 )}$ & $\mathbf{( n = 1 8 )}$ & $\mathbf{( n = 2 7 )}$ & $\mathbf{( n = 8 0 )}$ & $(\mathbf{n = 2 6 )}$ \\
\hline ANTES & & & & & \\
Frequentemente & $38,3 \%$ & $47,1 \%$ & $32,3 \%$ & $45,8 \%$ & $52,3 \%$ \\
Algumas vezes & $48 \%$ & $36,3 \%$ & $42,3 \%$ & $38,7 \%$ & $39,3 \%$ \\
Raramente & $13,4 \%$ & $12,4 \%$ & $24 \%$ & $12,5 \%$ & $8,3 \%$ \\
Não responderam & $0,3 \%$ & $0,2 \%$ & $1,4 \%$ & $2,9 \%$ & $0,9 \%$ \\
DURANTE & & & & & \\
Frequentemente & $45 \%$ & $48,9 \%$ & $43,03 \%$ & $57,62 \%$ & $61,4 \%$ \\
Algumas vezes & $43 \%$ & $36,1 \%$ & $32,9 \%$ & $32,7 \%$ & $30 \%$ \\
Raramente & $12 \%$ & $15 \%$ & $20 \%$ & $9,4 \%$ & $8,1 \%$ \\
Não responderam & - & $0,9 \%$ & $4 \%$ & $0,3 \%$ & $0,5 \%$ \\
DEPOIS & & & & & $27,8 \%$ \\
Frequentemente & $24,9 \%$ & $27,8 \%$ & $24,1 \%$ & $31,4 \%$ & $50,8 \%$ \\
Algumas vezes & $43,3 \%$ & $42,3 \%$ & $35,8 \%$ & $48,3 \%$ & $21,4 \%$ \\
Raramente & $26,4 \%$ & $25,9 \%$ & $38,9 \%$ & $18,4 \%$ & - \\
Não responderam & $5,5 \%$ & $4 \%$ & $1,3 \%$ & $1,9 \%$ & \\
\hline
\end{tabular}

Fonte: Do Autor 
A Tabela 3 permite que se constate que, entre os alunos participantes dos primeiros anos, muitos informaram utilizar frequentemente as estratégias antes da leitura. Destacam-se os alunos participantes dos cursos de Biologia (47,1\%), Letras Clássicas e Vernáculas $(45,8 \%)$ e de Filosofia $(52,3 \%)$. Os participantes dos outros dois cursos informaram usar essas estratégias algumas vezes: Geografia (48\%) e Matemática (42,3\%). Das estratégias previstas para serem utilizadas durante a leitura, constata-se que a maioria de todos os alunos participantes assinalou que frequentemente faz uso delas: Geografia (45\%), Biologia (48,88\%), Matemática (43,03\%), Letras Clássicas e Vernáculas (57,62\%), Filosofia $(61,42 \%)$. Em relação às seis estratégias estimadas no instrumento para serem usadas após a leitura, opção algumas vezes concentrou o maior número de alunos, com exceção dos participantes do Curso de Matemática em que a incidência maior registrada foi na opção raramente $(38,88 \%)$.

A Tabela 4 sistematiza os resultados verificados junto aos alunos participantes dos quartos anos, isto é, aos formandos dos cursos selecionados. Como pode ser observado no encontro dos participantes com os textos, antes de iniciar propriamente a leitura, $38,4 \%$ dos participantes do curso de Geografia, $48,2 \%$ de Biologia, 40,3\% de Matemática, 52,3\% de Letras Clássicas e Vernáculas e 54,5\% de Filosofia informaram que frequentemente utilizam essas quatro estratégias quando leem textos de estudo. Porém os participantes dos cursos de Geografia (48\%) e de Matemática (43\%) informaram que as utilizam apenas ocasionalmente.

Tabela 4. Uso das Estratégias de Leitura entre os Alunos Formandos das Licenciaturas.

\section{Uso das Estratégias de Leitura Geografia Biologia Matemática Letras Clássicas e Vernáculas Filosofia}

\begin{tabular}{llllll} 
& $\mathbf{( n = 5 7 )}$ & $\mathbf{( n = 4 1 )}$ & $\mathbf{( n = 1 8 )}$ & $\mathbf{( n = 2 6 )}$ & $\mathbf{( n = 1 1 )}$ \\
\hline ANTES & & & & & \\
Frequentemente & $38,4 \%$ & $48,2 \%$ & $40,3 \%$ & $52,3 \%$ & $54,5 \%$ \\
Algumas vezes & $48 \%$ & $28 \%$ & $43 \%$ & $37,5 \%$ & $31,8 \%$ \\
Raramente & $13,4 \%$ & $18,3 \%$ & $16,7 \%$ & $9,6 \%$ & $4,5 \%$ \\
Não responderam & $0,2 \%$ & $5,5 \%$ & $0,01 \%$ & $0,01 \%$ & $9,1 \%$ \\
DURANTE & & & & & $55,4 \%$ \\
Frequentemente & $50,7 \%$ & $58,5 \%$ & $50,5 \%$ & $65 \%$ & $21,8 \%$ \\
Algumas vezes & $35,3 \%$ & $31,5 \%$ & $33.3 \%$ & $26,9 \%$ & $13,6 \%$ \\
Raramente & $14 \%$ & $9 \%$ & $15,5 \%$ & $8,1 \%$ & $9,12 \%$ \\
Não responderam & - & $1 \%$ & $0,57 \%$ & - & \\
DEPOIS & & & & & $27,3 \%$ \\
Frequentemente & $24,8 \%$ & $28,4 \%$ & $19,4 \%$ & $27,6 \%$ & $31,8 \%$ \\
Algumas vezes & $48,2 \%$ & $43 \%$ & $50 \%$ & $43,6 \%$ & $31,8 \%$ \\
Raramente & $26,3 \%$ & $28,5 \%$ & $29,6 \%$ & $28,8 \%$ & $9,1 \%$ \\
Não responderam & $0,6 \%$ & - & $0,04 \%$ & $0,04 \%$ & \\
\hline
\end{tabular}

Fonte: Do Autor 
As estratégias previstas para uso durante a leitura propriamente dos textos, conforme informado pelos participantes, são frequentemente utilizadas por todos independente do curso em que se encontravam matriculados (50,7\% de Geografia, 58,5\% de Biologia, $50,5 \%$ de Matemática, 65\% de Letras Clássicas e Vernáculas, 55,4\% de Filosofia). Foram estratégias reconhecidas como importantes para serem usadas após a leitura aquelas que, na opção algumas vezes, obtiveram maior incidência independente do curso em que os participantes se encontravam matriculados (48,2\% de Geografia, 43\% de Biologia, 50\% de Matemática, 43,6\% de Letras Clássicas e Vernáculas, $32,8 \%$ de Filosofia).

Os resultados das Tabelas 3 e 4 atestam que os participantes formandos dos cursos de Matemática e de Letras Clássicas e Vernáculas reconhecem que utilizam com mais frequência estratégias previstas pelo instrumento para serem usadas antes e durante, quando comparados com os recém-ingressos nesses cursos. A leitura dessas tabelas permite, ainda, que se conclua que, proporcionalmente, mais participantes recém-ingressos nesses cursos informaram fazer uso mais frequente das estratégias propostas para após a leitura do que os formandos dos mesmos cursos.

Entre os participantes dos cursos de Geografia, Biologia e Filosofia, o reconhecimento do uso das estratégias antes e após a leitura é similar proporcionalmente entre recém-ingressos e formandos. De modo geral, mais participantes, independentemente da série em que se encontravam matriculados, utilizam-nas mais ocasionalmente do que frequentemente ou raramente. Entretanto as estratégias previstas para durante a leitura são reconhecidas pelos participantes de ambas as séries como utilizadas mais frequentemente do que algumas vezes ou raramente.

Os participantes dos cursos de Biologia e Filosofia, independente da série em que se encontravam matriculados, reconhecem utilizar mais frequentemente do que ocasionalmente e raramente as estratégias elencadas no instrumento para antes, durante e após a leitura. Todavia, tanto entre os recémingressos quanto entre os formandos destes cursos, mais participantes informaram que usam algumas vezes as estratégias previstas no após a leitura do que frequentemente ou raramente.

A partir dessa análise, foram comparados esses resultados por áreas de conhecimento dos cursos. Os cursos de Geografia e de Matemática são da área de Ciências Exatas. Apesar de fazerem parte da mesma área, os resultados obtidos por curso são distintos. Como relatado, no curso de Geografia, o uso das estratégias de leitura, independente da condição a que estavam associadas, isto é, antes, durante e após, são similares entre os ingressantes e os que estão concluindo, já entre os recém-ingressos no curso de Matemática, registra-se uma maior frequência de participantes informando que usam raramente as estratégias arroladas para após a leitura do que entre os formandos. Em relação aos participantes do curso de Biologia e aos de Letras Clássicas e Vernáculas as respostas dos ingressantes e dos formandos são similares quando comparados os índices de frequência de uso indicados para todas as fases da leitura.

Os resultados deste estudo não convergem com os obtidos por Pullin e Tanzawa (2009) junto ao curso de Pedagogia. Essas autoras verificaram que alunos ingressantes utilizam mais frequentemente as estratégias de leitura quando comparados com os participantes que estavam concluindo a graduação. Não convergem, ainda, com os de Silvia e Santos (2004), que registraram um desempenho melhor nos alunos mais velhos em relação aos mais jovens. Essas autoras destacaram a idade como um fator responsável pelo desenvolvimento de novos hábitos de leitura e de estudo.

Os dados do presente estudo permitem levantar a hipótese de que as áreas dos cursos nas quais os alunos participantes estavam matriculados e o fato de estarem ingressando ou concluindo seu curso não parecem ser variáveis relevantes para que se diferenciem os alunos quanto ao uso de estratégias de leitura. 


\section{Considerações Finais}

Ao longo de um curso de graduação, é de se esperar que os estudantes modifiquem e busquem utilizar com maior eficiência as estratégias que utilizam para a leitura de textos de estudo. Contudo, como advertem Santos et al., (2006, p. 86), “[...] os leitores com baixo rendimento em leitura parecem estar menos conscientes de suas falhas de vocabulário e de suas dificuldades [...]". A falta de consciência dos leitores - neste caso, de alunos universitários quanto às estratégias a serem utilizadas na leitura, aliada ao desconhecimento de quais sejam as mais eficientes para a leitura dos textos prescritos nas diferentes disciplinas têm sido relatados em estudos realizados no Brasil e no exterior como um dos impedimentos para que a leitura se constitua em um meio eficaz para a aprendizagem e os estudantes não se sintam incapazes quando devem produzir leituras de estudo (WITTER, 1997; CARLINO, 2003; PULLIN; MOREIRA, 2008, entre outros).

É importante, entretanto, mencionar a responsabilidade de professores do Ensino Superior para a formação de leitores. A formação de quaisquer leitores é um processo contínuo e uma das tarefas desses profissionais, independente da área (NEVES et al., 2003) e nível de ensino em que atuem. Quando assumem esse compromisso profissional, podem contribuir para que seus alunos, futuros profissionais, nunca deixem de ler e aprender para participarem criticamente dos grupos e da sociedade da qual fazem parte.

É preciso que os professores, como profissionais, propiciem condições para que os estudantes universitários estabeleçam para si metas de aprendizagem. Dessa maneira, poderão ficar motivados para buscar os suportes e as estratégias, entre estes os relacionados à leitura, que os auxiliem no alcance de suas metas. E, por conseguinte, assumam o controle de si e de seu desenvolvimento, pessoal e profissional.

Devido a um longo caminho já percorrido, muitas vezes, o professor propõe, expõe e avalia durante suas aulas, de tal modo que não incentiva seus alunos a apresentarem outras informações e reflexões, além daquelas enunciadas em sala de aula ou pelo autor do texto prescrito. Em alguns casos, quando prescrevem os textos, os professores deixam de apresentar informações importantes sobre ele, como a história do autor, o contexto no qual o texto foi produzido, ou outras informações essenciais que incentivem os alunos para os lerem. Em assim sendo, pouco instigam os alunos a compreenderem, de fato, a produção, nem a cotejá-la criticamente com os conhecimentos de que dispõem e com as produções de outros.

Entre os resultados, o fato de poucos participantes pensarem acerca das implicações das informações contidas nos textos de estudo é preocupante, especialmente em se tratando de alunos cuja formação acadêmica certifica-os para serem professores.

Se o professor tem grande responsabilidade na formação de leitores, é fundamental, entretanto, que os alunos estejam conscientes de seu papel como leitores e aprendizes. No Ensino Superior, especialmente em cursos de formação de professores, além do incentivo e estímulo para a leitura por parte dos professores, é necessário que os próprios alunos reflitam sobre o assunto e sejam capazes de reconhecer, avaliar e desenvolver novos modos e estratégias de leitura que lhes facultem novas aprendizagens. A satisfação no êxito desse tipo de leitura aumentará a probabilidade de eles incorporarem a leitura como um meio e prática importantes para que, futuramente, possam continuar a se atualizar de forma independente. Desse modo, poderão não só continuar a "aprender a aprender" de modo autônomo, como incentivarem outros a fazê-lo.

Isso ocorre com a prática, porque, mediante o exercício, desenvolve-se o hábito e o modo do leitor se acercar dos textos prescritos ou não para estudo. Castello-Pereira (2003, p. 203) destaca: 
Procedimentos, estratégias, planejamento, postura do professor são realmente fatores importantes no ensino da leitura, agora, não podemos deixar de enfatizar que serão as repetidas experiências com a leitura que transformarão os alunos universitários em leitores autônomos.

Conforme relatado, a frequência de uso de estratégias que facilitem a leitura dos textos prescritos na universidade parece não diferenciar alunos recém-ingressos dos formandos. Esses resultados não convergem, por exemplo, com os resultados constatados por Pullin e Tanzawa (2009) e com os obtidos por Silva e Santos (2004). Nesses trabalhos, as autoras constataram um uso mais apropriado dessas estratégias entre alunos formandos.

Os resultados descritos neste estudo reforçam os argumentos de especialistas (WITTER, 1997; CARLINO, 2003) quanto à necessidade dos professores universitários se preocuparem com os textos que prescrevem e os modos de seus alunos produzirem suas leituras.

\section{Referências}

BAMBERGER, R. Como incentivar o hábito de leitura. 2. ed. São Paulo: Ática, 1986.

BATISTA, A. A. G. Os parâmetros, os professores e as formas brandas de exclusão. In: MARCUSCHI, E. (Org.). Formação do educador, avaliação e currículo. Recife: EdUFPE, 1999. p. 53-78.

. Os professores são 'não-leitores'? In: MARINHO, M.; SILVA, C. S. R. Leituras do professor. Campinas: Mercado de Letras, 1998. p. 23- 60.

BRASIL. Ministério da Educação. Lei de Diretrizes e Bases da Educação Nacional. 1996. Disponível em: $<$ http://portal.mec.gov.br/arquivos/pdf/ldb.pdf $>$. Acesso em: 15 out. 2010.

Secretaria de Educação Fundamental. Parâmetros Curriculares Nacionais. 2004. Disponível em: $<$ http://portal.mec.gov.br/seb/arquivos/pdf/livro01. pdf $>$. Acesso em: 15 out. 2010.

CARLINO, P. Alfabetización académica: un cambio necesario, algunas alternativas posibles. Educere,
Mérida, v. 6, n. 20, p. 409-420, 2003.

CASTELLO-PEREIRA, L. T. Leitura de estudo: ler para aprender a estudar e estudar para aprender a ler. Campinas: Alínea, 2003.

FREIRE, P. Considerações em torno do ato de estudar. In: . Ação cultural para a liberdade e outros escritos.

6. ed. Rio de Janeiro: Paz e Terra, 1982. p. 9-12.

Ensinar, aprender: leitura do mundo, leitura da palavra. Estudos Avançados, São Paulo, v. 15, n. 42, p. 259-268, 2001.

GIMENO- SACRISTÁN, J. A educação que ainda é possivel: ensaios sobre a cultura para a educação. Porto: Portoed, 2008. p. 85-109.

GUEDES, P. C.; SOUZA, J. M. Leitura e escrita são tarefas da escola e não só do professor de português. In: NEVES, I. C. B. (Org.). Ler e escrever: compromisso de todas as áreas. 5. ed. Porto Alegre: UFRGS, 2003. p. 15-20.

KONS, M. L. Vestígios de poder em práticas de leitura. Revista da UFG, v. 7, n. 2, 2005. Disponível em: <www. proec.ufg.br>. Acesso em: 15 mar. 2009.

KOPKE FILHO, H. Estratégias em compreensão da leitura: conhecimento e uso por professor de língua portuguesa. 2001. $148 \mathrm{f}$. Tese (Doutorado em Linguística) - Faculdade de Filosofia Ciências e Letras, Universidade de São Paulo, São Paulo.

Repertório de estratégias de compreensão da leitura e conhecimento metacognitivo de professores de língua portuguesa. Psicologia Escolar e Educacional, Campinas, v. 6, n. 1, p. 67-80, 2002.

MARTINS, R. M. M.; SANTOS, A. A. A.; BARIANI, I. C. D. Estilos cognitivos e compreensão leitora em universitários. Paidéia, Ribeirão Preto, v. 15, n. 30, p. 57-68, 2005.

NEVES, I. C. B.; SOUZA, J. V.; SCHÄFFER, N. O.; CUEDES, P. C.; KLÜSENER, R. Ler e escrever: compromisso de todas as áreas. 5. ed. Porto Alegre: EDUFRGS, 2003.

NÓVOA, A. António Nóvoa fala sobre conteúdos que devem ser prioritários na escola. Revista Gestão Escolar, São Paulo, jul. 2010. Entrevista concedida à Cinthia Rodrigues. Disponível em: $<$ http://revistaescola. abril.com.br/gestao-escolar/diretor/antonio-novoafala-conteudos-devem-ser-prioritarios-escola-574267. shtml>. Acesso em: 15 jan. 2011.

OLIVEIRA, K. L.; SANTOS, A. A. A. Compreensão em leitura e avaliação em universitários. Psicologia: Reflexão e Crítica, São Paulo, v. 18, n. 1, p. 118-124, 2005. 
PULLIN, E. M. M. P. Leitura de estudo: estratégias reconhecidas como utilizadas por alunos universitários. Ciências \& Cognição, Rio de Janeiro, v. 12, p. 51-61, 2007.

PULLIN, E. M. M. P.; MOREIRA, L. S. G. Prescrição de leituras na escola e formação de leitores. Ciências \& Cognição, Rio de Janeiro, p. 231-242, 2008.

PULlin, E. M. M. P.; PULlin, A. M. P. Leitura de alunas de um mestrado em educação: implicações para o ensino e pesquisa. In: CONGRESSO ESTADUAL PAULISTA SOBRE FORMAÇÃO DE EDUCADORES, 8., 2007, São Paulo. Anais... São Paulo: Unesp, 2007. p. 28-38.

PULlin, E. M. M. P.; TANZAWA, E. C. L. Futuros professores e textos acadêmicos: como lêem e se auto-avaliam. In: CONGRESSO NACIONAL DE EDUCAÇÃO, 9, 2009, Curitiba. Anais... Curitiba: PUCPR, 2009. Disponível em: <http://www.pucpr.br/ eventos/educere/educere2009/anais/pdf/2891_2155. pdf $>$. Acesso em: 6 jul. 2010.

SANTOS,A.A.A.;VENDRAMINI, C.M.M.; SUEHIRO, A. C. B.; SANTOS, L. A. D. Leitura compreensiva e utilização de estratégias de aprendizagem em alunos de psicologia. Estudos de Psicologia, Campinas, v. 23, n. 1, p. 83-91, 2006.

SILVA, M. J. M.; SANTOS, A. A. A. A avaliação da compreensão em leitura e o desempenho acadêmico de universitários. Psicologia em Estudo, Maringá, v. 9, n. 3, p. 459-467, 2004.

TEDESCO, J. C. Los desafíos de la educación básica en el siglo XXI. Revista Iberoamericana de Educación, Madrid, n. 55, p. 31-47, 2011.

WITTER, G. P. Produção e leitura do texto científico. Estudos de Psicologia, Campinas, v. 9, n. 1, p. 19-26, 1996.

Psicologia: leitura \& universidade. Campinas:

Alínea, 1997.

Recebido em: março 2010

Aceito em: julho 2010 